\title{
Microbubble Distillation for Ethanol-Water Separation
}

\author{
Atheer Al-yaqoobi, ${ }^{1}$ David Hogg, ${ }^{2}$ and William B. Zimmerman ${ }^{1}$ \\ ${ }^{1}$ Department of Chemical and Biological Engineering, University of Sheffield, Mappin Street, Sheffield S1 3JD, UK \\ ${ }^{2}$ Rejuvetech Ltd., The Sheffield Bio-Incubator, 40 Leavygreave Road, Sheffield S3 7RD, UK
}

Correspondence should be addressed to Atheer Al-yaqoobi; cppllama@sheffield.ac.uk

Received 1 January 2016; Accepted 14 March 2016

Academic Editor: Junwu Wang

Copyright (C) 2016 Atheer Al-yaqoobi et al. This is an open access article distributed under the Creative Commons Attribution License, which permits unrestricted use, distribution, and reproduction in any medium, provided the original work is properly cited.

\begin{abstract}
In the current study, a novel approach for separating ethanol-water mixture by microbubble distillation technology was investigated. Traditional distillation processes require large amounts of energy to raise the liquid to its boiling point to effect removal of volatile components. The concept of microbubble distillation by comparison is to heat the gas phase rather than the liquid phase to achieve separation. The removal of ethanol from the thermally sensitive fermentation broths was taken as a case of study. Consequently the results were then compared with those which could be obtained under equilibrium conditions expected in an "ideal" distillation unit. Microbubble distillation has achieved vapour compositions higher than that which could be obtained under traditional equilibrium conditions. The separation was achieved at liquid temperature significantly less than the boiling point of the mixture. In addition, it was observed that the separation efficiency of the microbubble distillation could be increased by raising the injected air temperature, while the temperature of the liquid mixture increased only moderately. The separation efficiency of microbubble distillation was compared with that of pervaporation for the recovery of bioethanol from the thermally sensitive fermentation broths. The technology could be controlled to give high separation and energy efficiency. This could contribute to improving commercial viability of biofuel production and other coproducts of biorefinery processing.
\end{abstract}

\section{Introduction}

Distillation columns are one of the oldest and most important pieces of equipment used in the chemical and petrochemical industries. In addition to the large capital costs required for the installation of the plant, the operational costs are also high due to the energy intensive nature of the procedure, in particular the reboiler and the condenser units requiring the lion's share of the energy input of the overall process.

The simple distillation unit is a fundamental module of complex multicomponent separations by distillation. Basically, in this process the vapour rising as a result of boiling of the liquid in the still is richer in more volatile component than the residual liquid. The composition of vapour leaving the liquid phase is in thermodynamic equilibrium with the liquid phase [1]. The vapour composition is determined by net effect of combination temperature, pressure, and liquid composition [2].

For design purposes, thermodynamic equilibrium is assumed to be established between the vapour and liquid leaving each stage. Practically, in actual operation, both phases leave the stage without achieving equilibrium [3]. Usually, stage efficiency is used to estimate the real vapour composition that leaves the tray which is typically between one-third and one-half of the theoretical change possible that the equilibrium composition could achieve. The deviation of the tray efficiency from the theoretical stage can be compensated through an increase in column height and reflux ratio. To achieve this improvement, additional capital and operating cost is required which includes provision for larger heat exchangers and pumps, leading to a significant increase in energy demand.

Distillation is commonly used in the biorefinery processing of bioethanol production. This adds a significant energy load on the production process. The estimation showed that more than half of the total production energy is consumed by distillation [4]. Consequently, to make bioethanol production processing commercially competitive with the fossil fuel industry, reducing the production costs is of the utmost importance. In addition, accumulation of bioethanol in 
the fermentation bioreactor inhibits the activity of microorganisms. An ethanol concentration of approximately $63 \mathrm{~g} / \mathrm{L}$ can cause damage to the membrane of an organism's cell wall. At higher concentrations of around $95 \mathrm{~g} / \mathrm{L}$, the cell growth of yeast is inhibited by ethanol [5]. One of the ways to overcome this problem is to remove the products from the fermentation bioreactor by a continuous separation unit, where the ethanol is extracted from the broth during the fermentation process [6]. That method was found to be effective in preventing the inhibition of microorganisms and increases ethanol productivity markedly [4]. The microorganisms used in fermentation processes are thermally sensitive; consequently, the overheating of the fermentation broth media in the separation unit used in above-mentioned scenario should be considered [7].

Recently, the evaporation dynamics of hot microbubbles in air-water systems have been studied [8]. The computational model presents the concept of nonequilibrium evaporation by heating the gas phase rather than the liquid phase. In traditional distillation the liquid is boiled to achieve the maximum equilibrium vapour pressure. The computational model hypothesis takes into consideration the internal gas dynamics of the bubble. The model predicts the impact of microbubble features on the mechanisms of sensible heat transfer and evaporation. The model shows that, by controlling the bubble residence time in the liquid phase, maximum evaporation can be achieved. The maximum absolute humidity is obtained a short time after bubble detachment. Thereafter, if the bubble was still hotter than the surrounding liquid, the contact between the bubble and the liquid phase promotes sensible heat transfer from the bubble to the liquid. This sensible heat transfer cools the bubble and is accompanied by recondensation of vapour back into the liquid phase.

The microbubble humidification-dehumidification modelling and experimental work showed a potentially novel approach for applying the technology to the separation of liquid mixtures. The use of microbubble distillation was used in the separation of binary mixtures effectively as a first step towards using the technology in potentially complex mixtures.

The aim of the current work was to investigate the performance of microbubble distillation of a binary mixture, with the exemplar of ethanol-water separation. A second objective was to compare the efficiency of a microbubble distillation unit with the simple distillation unit as a potential replacement for traditional distillation. Microbubble distillation was expected to achieve separation higher than that achieved by traditional distillation due to the nonequilibrium conditions imposed by injecting hot microbubbles into a colder liquid. Consequently, the vapour-liquid composition of microbubble distillation was compared with the vapourliquid composition achieved under equilibrium conditions, since the traditional distillation was based on achieving the equilibrium operating conditions. In addition, the effect of air temperature on the stripping of ethanol from the water/ethanol mixtures and the performance of microbubble distillation was also investigated. The study highlighted the possible feasibility of microbubble distillation technology for the recovery of ethanol from fermentation broths. All

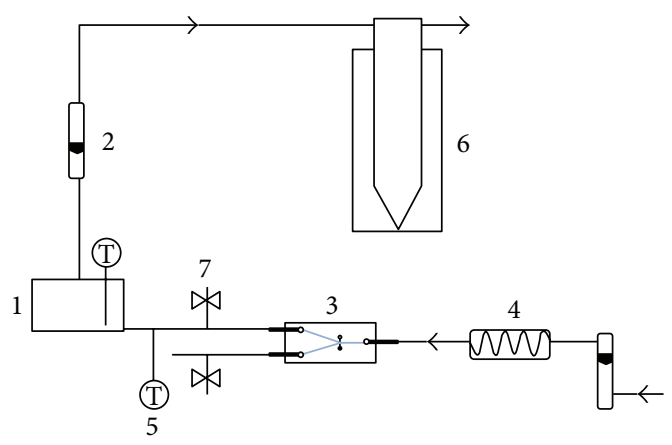
(1) Separation tank
(2) Flowmeter
(5) Thermometer
(3) Fluidic oscillato
(4) Air process heater
(6) Condenser
(7) Bleeding valve

FIgURE 1: Schematic diagram of the experimental rig setup.

experiments were conducted with the use of energy efficient fluidic oscillation to produce microbubbles.

This paper is organised as follows: Section 2 is dedicated to the experimental methodology, the experiment setup, equipment and materials used in the experimental procedure, and the analysis method. Results and discussion are presented in Section 3. Finally, Section 4 summarises conclusions.

\section{Experimental Work}

2.1. Experimental Apparatus and Material. The microbubble distillation experiments were performed using a semibatch system. Liquid mixtures were charged into the separation tank initially, but there was a continuous flow of gas through the liquid via microbubble injection. The off-gases were collected by use of a suitable condenser. The schematic diagram of the experimental setup is shown in Figure 1. The separation tank was made of glass fixed on a $145 \times$ $80 \mathrm{~mm}$ stainless steel base. The base was provided with a microporous diffuser of $60 \mathrm{~mm} \times 125 \mathrm{~mm}$ dimensions and $5 \mathrm{~mm}$ thickness manufactured by Point Four Systems Inc. The air was heated by using a heater made by RS Components Ltd. with power of $750 \mathrm{~W}$. The air stream was heated and fed to the fluidic oscillator and then to the separation tank. The desired flow rate was measured from the tank outlet and controlled by the use of bleeding valves, which vented the excess air from the outlet of the oscillator. The off-gas was connected to a glass condenser of $85 \mathrm{~mm}$ diameter and $350 \mathrm{~mm}$ height as shown in Figure 2. Conical appendages were made on the inner surface of the condenser to increase the contact with the available surface area of the condenser. The vapour entered from the top of the condenser and split towards the condenser walls by using a Y-joint splitter. Appendages formed in this way guaranteed that the drops of liquid condensed on the surface and then drained to the bottom of the condenser, where the condensed liquid was collected. The off-gases which were permanent gases exited from the top of the condenser. The sample of the condensed liquid was collected from the bottom of the condenser. An ice and salt mixture was used as 


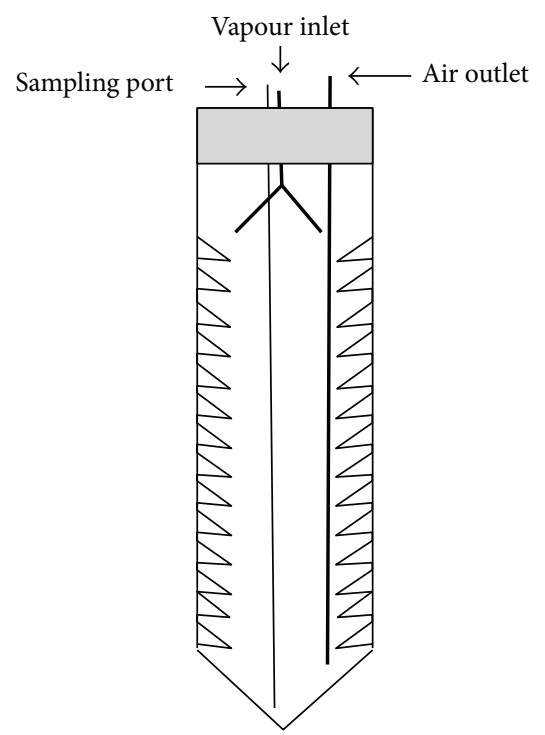

FIgURE 2: Schematic diagram of the condenser.

a coolant to maintain the condenser at $-19^{\circ} \mathrm{C}$ to $-20^{\circ} \mathrm{C}$. The system was insulated by using glass wool thermal insulation.

The K-type $\left(\mathrm{Ni} \mathrm{Cr}{ }^{+} / \mathrm{Ni} \mathrm{Al}^{-}\right)$thermocouples were used to measure the temperature in the system. The entire pipework was made from steel in order to bear the high working temperatures. The fluidic oscillator was constructed from aluminium. The binary mixture used in the experiments was distilled water and ethanol (HPLC grade) with purity of $\geq 99.8 \%$ provided by Sigma-Aldrich, UK.

The initial volume of the liquid in the tank was prepared according to the required liquid level above the diffuser. The approximate volume was calculated as follows:

$$
V_{\text {required }}=\text { Area of the tank base } * H \text {, }
$$

where $(H)$ is the required liquid level.

The desired liquid mixture was prepared and mixed well in a cold water bath to maintain the liquid temperature around $20^{\circ} \mathrm{C}$. The air was supplied to the heater at a flow rate of 80 litres $/ \mathrm{min}$. The liquid mixture of ethanol and water was poured into the tank, after the desired air temperature was reached.

Samples of the liquid from the condenser and residue liquid were taken periodically. The temperature reading was taken every ten minutes.

2.2. Bubble Measuring. The bubble sizing was conducted via a Spraytec system (Malvern Instrument, UK). The method was based on the diffraction in the laser beam to infer bubble sizes of equivalent spheres. The Spraytec system has two arms where the apparatus was placed between the arms. The laser beam emitted from the light source was fixed on one of the arms which then passed through the apparatus and was then received by series of detectors fixed on other arms. The laser beam was scattered by the bubble cloud during its path through the apparatus; consequently, the scattered light is focused by lens onto the detector. Thereafter, the data

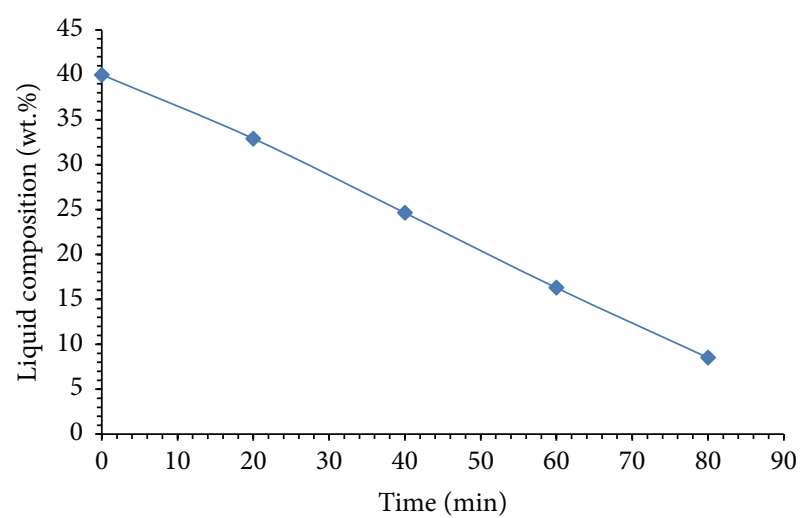

FIGURE 3: The change in liquid composition at initial liquid composition of $40 \%$ and air temperature of $150^{\circ} \mathrm{C}$.

from the scattering laser beam was processed by the Spraytec software to calculate the size distribution of bubbles via an inverse method for consistency with Fraunhofer diffraction pattern.

2.3. Analysis. All the samples were analyzed by a Bruker ALPHA FTIR-ATR spectrometer. The resolution was set to $4 \mathrm{~cm}^{-1}$ and the spectrum was taken with a scan region from 350 to $4500 \mathrm{~cm}^{-1}$. OPUS version 6 software was used for the sample spectrum analysis. The calibration curve was made based on the ethanol peak that appeared at $1045 \mathrm{~cm}^{-1}$. Each sample was repeated three times.

\section{Results}

The previous study of hot microbubble humidification showed that the liquid level had a significant effect on the vapour-liquid composition in microbubble distillation. The lower liquid levels showed a higher vapour composition than that achieved with higher liquid level under the same experimental conditions $[8,10]$. Accordingly, this set of experiments was conducted at a liquid level of $3.5 \mathrm{~mm}$ to study the vapourliquid composition obtained from microbubble distillation. Bearing this in mind, the liquid level was estimated according to the volume of liquid present in the tank. The injected air temperature was maintained at $150^{\circ} \mathrm{C}$ and four liquid mixtures of $10 \%, 25 \%, 40 \%$, and $60 \%$ were chosen to investigate the vapour-liquid composition obtained with microbubble distillation.

Figure 3 shows the change in liquid composition during the bubbling process at an initial liquid concentration of $40 \%$. The liquid composition reduced sharply with time due to the high evaporation of ethanol at the low liquid level.

The vapour composition which is represented by the liquid accumulated in condenser during the experimental time is shown in Figure 4. The results indicated that the vapour composition was influenced by the reduction in the liquid concentration. The first fraction that accumulated in the condenser collected after 20 min was $81.7 \%$; concurrently, the liquid composition decreased to approximately $32 \%$. 


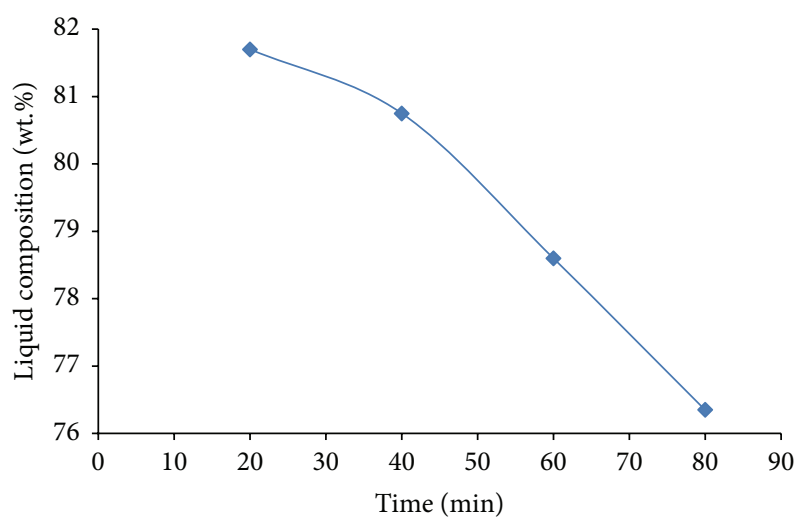

FIGURE 4: The concentration of the liquid accumulated in the condenser with time at liquid level.

Subsequently, the vapour phase composition decreased as the liquid phase composition decreased.

However, to study the vapour-liquid composition of microbubble distillation at different liquid concentrations, the first fraction that accumulated in the condenser was considered as the vapour composition at the initial liquid composition, even though the liquid composition was reduced to a lower value during the sampling time.

Figure 5 shows the vapour-liquid composition of microbubble distillation at different liquid concentrations. The compositions of the vapour phase obtained from microbubble distillation were $57.8 \%, 75.5 \%, 81.7 \%$, and $84.9 \%$ for initial liquid composition of $10 \%, 25 \%, 40 \%$, and $60 \%$, respectively. The average liquid temperature at all liquid compositions for most of the experimental time was around $36-38^{\circ} \mathrm{C}$ as shown in Figure 6 . However, the liquid temperature profile showed that the liquid temperature increased as the liquid mixture concentration decreased. The average liquid temperature at a liquid concentration of $10 \%$ was around $38.5^{\circ} \mathrm{C}$, and the average liquid temperature at a liquid concentration of $60 \%$ was around $37^{\circ} \mathrm{C}$.

The mechanism of microbubble distillation is proposed by a computational model developed by [8]. Later on the concept was tested with a binary system of ethanol and water [10]. After the injection of hot microbubbles in the cold liquid mixture, the components flash to a maximum concentration which is proportional to the bubble temperature. An additional nonequilibrium driving force came from the fact that the bubble injected was dry which provided additional mass transfer impetus for ethanol to join the vapour phase. The model also showed that the microbubble had an isothermal temperature profile inside the bubble. The microbubble had vigorous internal mixing due to the high surface area to volume ratio, which enhanced the ability for ethanol to reach the maximum concentration in such a short time.

The microbubble generated by the fluidic oscillator has a smaller heat transfer coefficient in comparison with bigger bubble. This is due to the laminar pattern of the microbubble through the liquid which gently detached from the pores of the diffuser $[8,11-13]$. This advantage gives the preference for evaporation to dominate over the sensible heat transfer

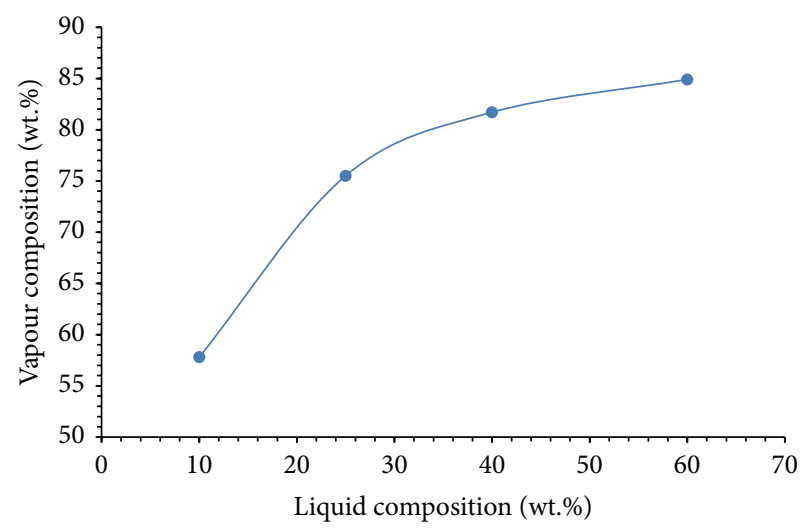

FIGURE 5: The vapour-liquid composition of microbubble distillation with different liquid composition at air temperature of $150^{\circ} \mathrm{C}$.

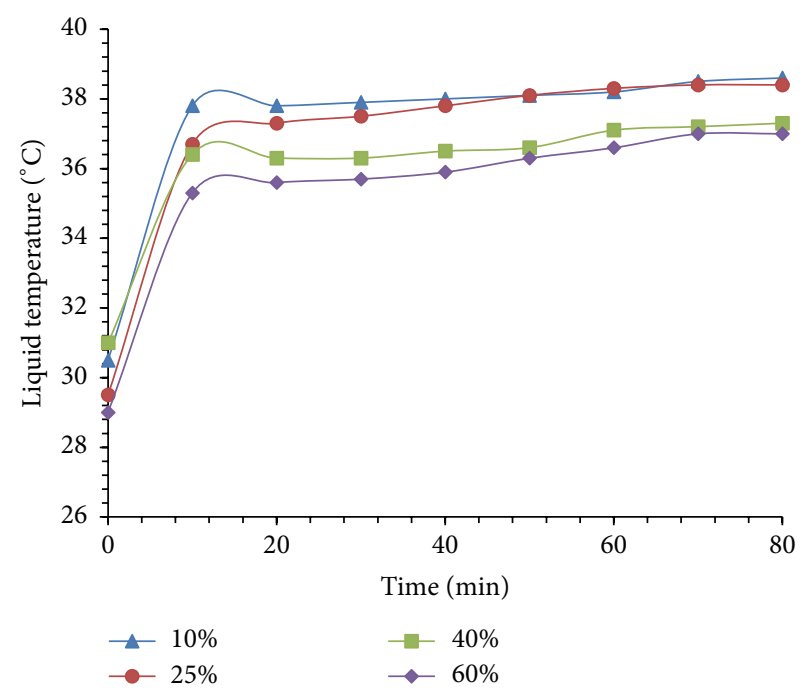

FIGURE 6: Liquid temperature profile with different liquid concentration at air temperature of $150^{\circ} \mathrm{C}$.

during the bubble rising through liquid until the maximum concentration is achieved. Furthermore, Zimmerman et al. [12] pointed out that the microbubbles cloud has high surface area to volume ratio which resulted in high interfacial area. This results in a high mass transfer flux, which is improved by a high interfacial area.

It is known that a very large amount of energy is required to raise the temperature of the mixture to the boiling point in a traditional distillation unit, which makes the operation a very energy intensive technology. On the other hand, the essential advantage of the microbubble distillation is that the separation was achieved at a temperature significantly below the boiling point of the mixture. The comparison between the traditional distillation process and the microbubble distillation technology was based upon the differences between the thermal and separation efficiencies. The liquid temperature and the composition of vapour phase obtained in both methods are highlighted in the following section. 
The boiling point of the liquid mixture can be estimated in terms of Raoult's law and Dalton's law as follows:

$$
P=P_{\mathrm{eth}}^{*} \cdot x_{1} \cdot \gamma_{1}+P_{w}^{*} \cdot x_{2} \cdot \gamma_{2},
$$

where $P$ is the total pressure, $\gamma_{i}$ is the activity coefficient of the component, and $P^{*}$ is the vapour pressure of pure ethanol and water estimated from the following Antoine equations:

$$
\begin{aligned}
\ln P_{w}^{*}= & 74.475-\frac{7164.3}{T}-7.327 \ln (T)+3.13 * 10^{-6} \\
& * T^{2}, \\
\ln P_{\text {eth }}^{*}= & 72.55-\frac{7206.7}{T}-7.1385 \ln (T)+4.05 * 10^{-6} \\
& * T^{2} .
\end{aligned}
$$

The activity coefficient of each component can be estimated according to the NRTL model:

$$
\begin{aligned}
& \ln \left(\gamma_{1}\right) \\
& =x_{2}^{2}\left[\tau_{21} \cdot\left(\frac{G_{21}}{x_{1}+x_{2}}\right)^{2}+\tau_{12} \cdot \frac{G_{12}}{\left(x_{2}+x_{1} \cdot G_{12}\right)^{2}}\right], \\
& \ln \left(\gamma_{2}\right) \\
& =x_{1}^{2}\left[\tau_{12} \cdot\left(\frac{G_{12}}{x_{2}+x_{1}}\right)^{2}+\tau_{21} \cdot \frac{G_{21}}{\left(x_{1}+x_{2} \cdot G_{21}\right)^{2}}\right],
\end{aligned}
$$

where

$$
G_{i j}=\exp \left(-0.3 \cdot \tau_{i j}\right), \quad \tau_{i j}=\frac{A_{i j}}{R T} .
$$

The binary interaction parameters of ethanol and water at a total pressure of $101.3 \mathrm{KPa}$ are [14]

$$
\begin{aligned}
& A_{12}=-633, \\
& A_{21}=5823.1 .
\end{aligned}
$$

The boiling temperature of the liquid mixture was calculated by solving the nonlinear equation result from substitution equations (3) and (4) in (2).

The equilibrium vapour composition for the liquid mixture is estimated according to modified Raoult's law:

$$
y_{i}=\frac{P_{i}^{*} \cdot \gamma_{i} \cdot x_{i}}{P} .
$$

Figure 7 shows the estimated boiling temperature and vapour composition according to the equilibrium conditions. The $T-x y$ diagram shows that the boiling point of liquid mixture is varied with the mixture composition. The estimate boiling point of the mixture of $10 \%$ is $91.6^{\circ} \mathrm{C}$ and the boiling point of the mixture declines with increasing of the ethanol percentage in the mixture, where the boiling point decreased to $82.4^{\circ} \mathrm{C}$ at liquid composition of $60 \%$. However, in comparison with microbubble distillation, a high vapour composition

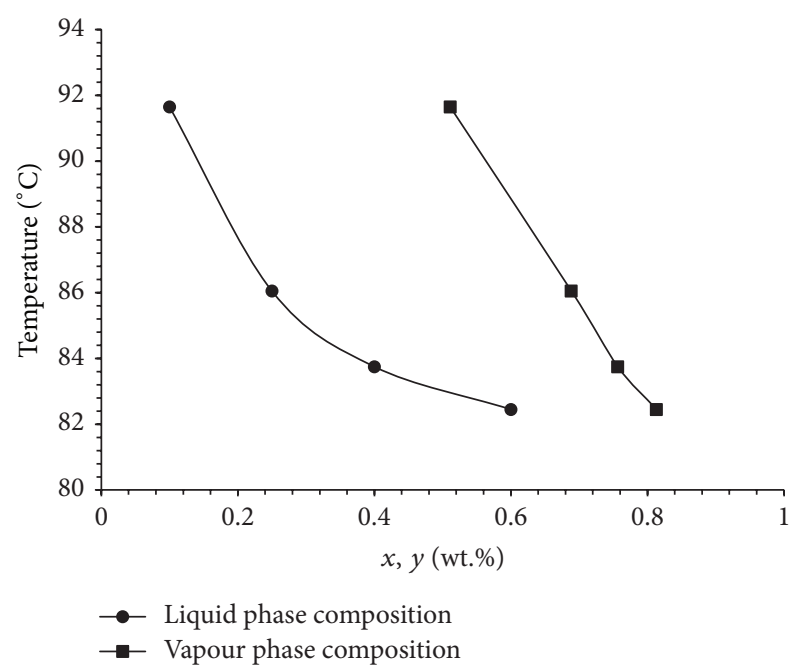

FIgURE 7: T-xy diagram for the ethanol and water mixture at equilibrium condition.

is achieved at a liquid temperature significantly below the boiling point of mixture, where the liquid temperature ranged from 36 to $38^{\circ} \mathrm{C}$ as shown in Figure 6. It is worth mentioning that the presence of a noncondensable gas in the gas stream allows the evaporation of the mixture components below its boiling point.

The estimated equilibrium vapour composition and the vapour composition achieved with microbubble distillation at different liquid compositions are presented in Figure 8. As is evident from Figures 7 and 8 vapour composition obtained from microbubble distillation is higher than vapour composition obtained from boiling the mixture at equilibrium conditions. The separation of higher purity of ethanol can be achieved by microbubble distillation processing compared to a traditional distillation stage which is limited at best to the equilibrium composition. Bear in mind that the equilibrium composition was never achieved in the conventional distillation unit, where the efficiency fraction is less than unity.

3.1. Effect of Air Stream Temperature. The studies $[9,15,16]$ on the isothermal vapour-liquid equilibrium composition of ethanol and water mixtures at different temperatures showed that increasing the liquid temperature leads to lower concentrations of ethanol in the vapour phase, as shown in Figure 9.

However, it was demonstrated that, by increasing the air temperature in microbubble distillation, different trends were obtained from that of equilibrium operation. The results presented for the effect of air temperature on vapour-liquid composition achieved by microbubble distillation showed that by an increase of the air temperature the vapour composition increased as the liquid composition decreased.

The effect of air temperature on the microbubble distillation was studied at air temperatures of $120^{\circ} \mathrm{C}$ and $150^{\circ} \mathrm{C}$ for liquid compositions of $25 \%$ and $40 \%$ and a liquid level of $3.5 \mathrm{~mm}$. Figure 10 shows the composition of the vapour phase at different air temperatures with initial liquid concentrations 


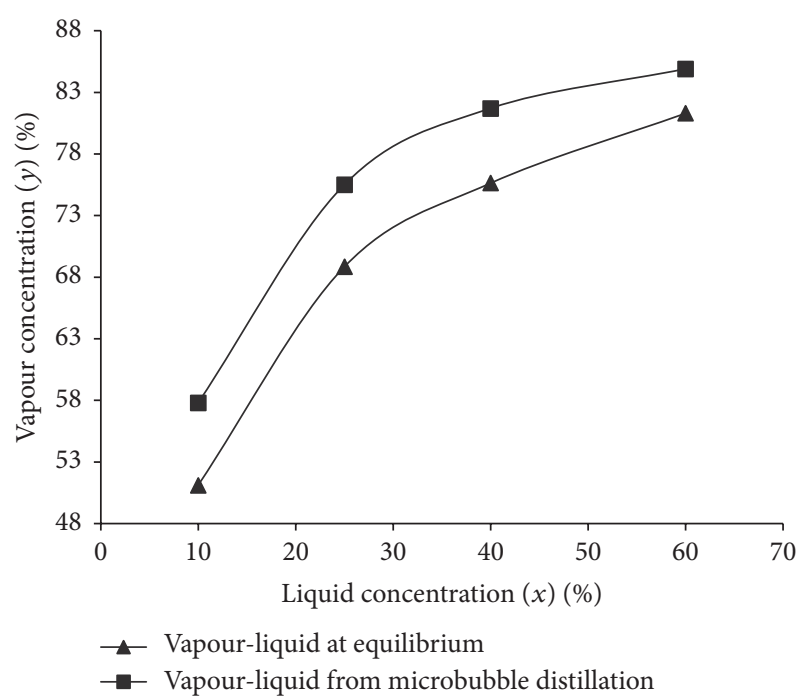

Figure 8: Comparison between the vapour-liquid compositions at equilibrium and the vapour-liquid composition result from the microbubble distillation at air temperature of $150^{\circ} \mathrm{C}$ (current work).

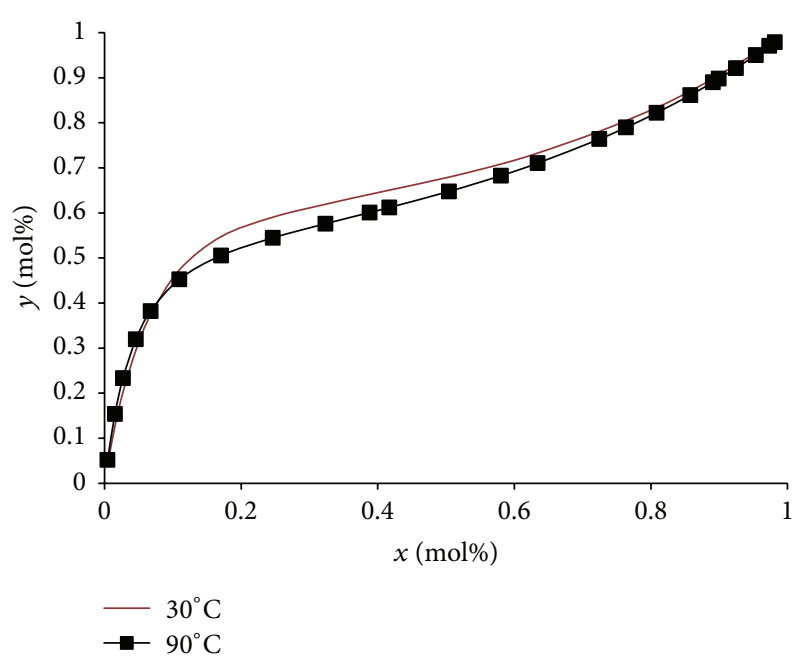

FIGURE 9: Vapour-liquid equilibrium composition at temperature of $30^{\circ} \mathrm{C}$ and $90^{\circ} \mathrm{C}[9]$.

of $40 \%$ and $25 \%$. The vapour phase composition increased from $78.8 \%$ at an air temperature of $120^{\circ} \mathrm{C}$ to around $81.7 \%$ at an air temperature of $150^{\circ} \mathrm{C}$ with a liquid concentration of $40 \%$. Likewise, the vapour phase increased from $70.5 \%$ to $75.5 \%$ when the air temperature increased from $120^{\circ} \mathrm{C}$ to $150^{\circ} \mathrm{C}$ at a liquid concentration of $25 \%$.

Accordingly, the residual liquid concentration shows obvious effects of air temperature on the separation performance as shown in Figures 11 and 12. With a liquid concentration of $25 \%$, the liquid concentration dropped to around $6.5 \%$ at an air temperature of $150^{\circ} \mathrm{C}$, whilst at an air temperature of $120^{\circ} \mathrm{C}$ the final liquid concentration was $11.8 \%$. Similar behaviour was observed with a liquid concentration of $40 \%$ with a different air temperature. The final liquid

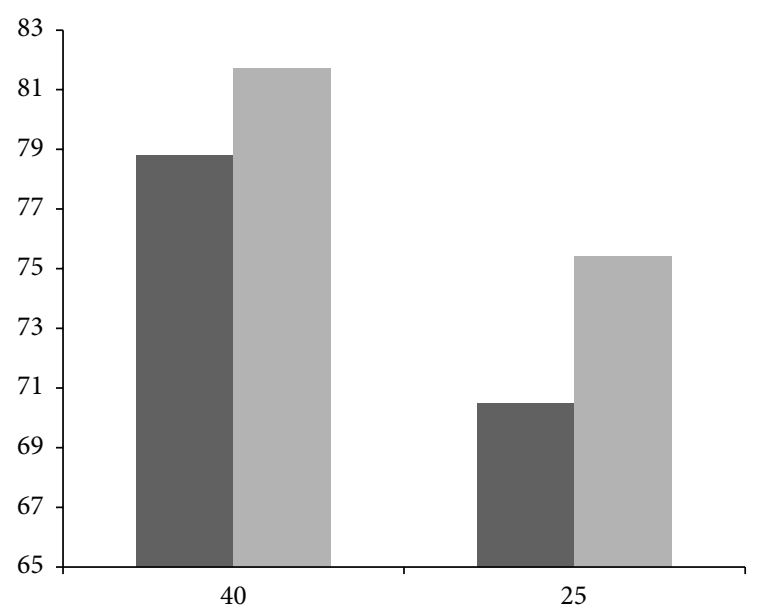

(\%)

$-120^{\circ} \mathrm{C}$
$-150^{\circ} \mathrm{C}$

FIGURE 10: The vapour phase composition with air temperature of $120^{\circ} \mathrm{C}$ and $150^{\circ} \mathrm{C}$ at liquid composition of $40 \%$ and $25 \%$.

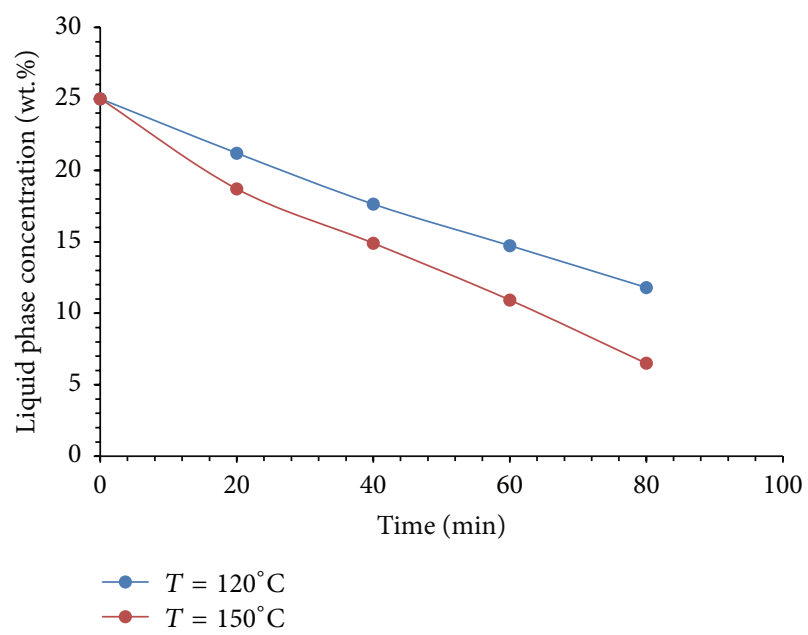

FIGURE 11: Liquid level profile with liquid concentration of $25 \%$ at air temperature of $120^{\circ} \mathrm{C}$ and $150^{\circ} \mathrm{C}$.

concentration decreased from $22 \%$ to $8.5 \%$ by increasing the temperature from $120^{\circ} \mathrm{C}$ to $150^{\circ} \mathrm{C}$.

The temperature of the liquid mixture increased as the air temperature increased in both liquid mixtures as in Figure 13. Although the trend of the liquid temperature was the same for both liquid concentrations, the increase in liquid temperature at a lower liquid concentration of $25 \%$ is higher. The sources of heat transfer to the liquid phase came from the bubbles and the gas distribution, assuming the heat loss to the periphery was low due to efficient insulation [17]. The result showed that the vapour concentration increased as the liquid concentration increased. Consequently, the required latent heat increased to satisfy the maximum vapour concentration required, where the latent heat was drawn from the system enthalpy and resulted in a decrease in the system temperature. 


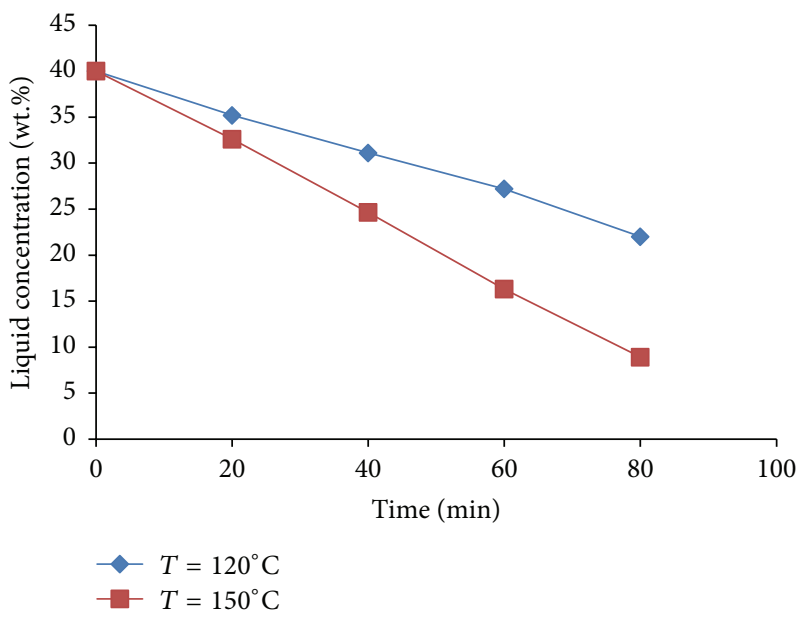

FIGURE 12: Liquid concentration profile with liquid concentration of $40 \%$ at air temperature of $120^{\circ} \mathrm{C}$ and $150^{\circ} \mathrm{C}$.

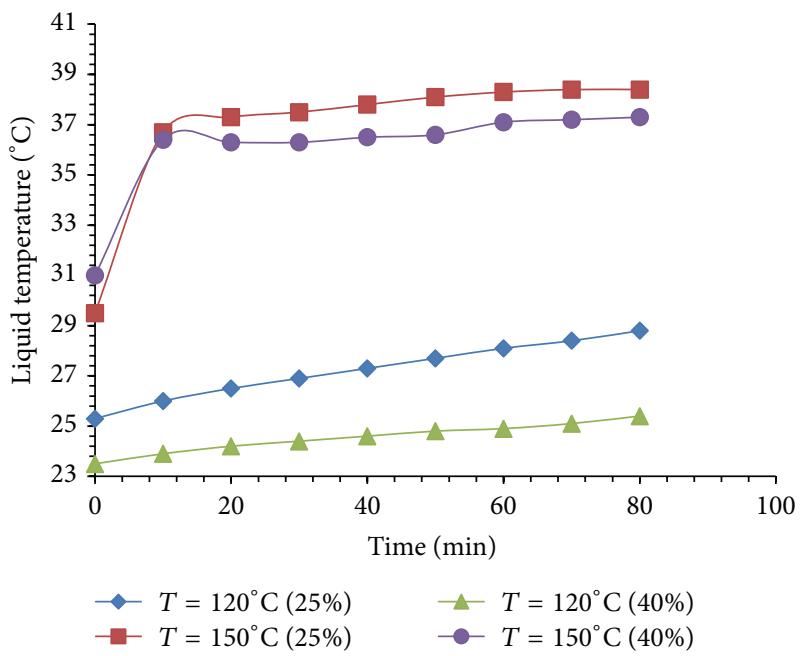

FIGURE 13: Liquid temperature profile for liquid concentration of $25 \%$ and $40 \%$ at air temperature of $120^{\circ} \mathrm{C}$ and $150^{\circ} \mathrm{C}$.

The reason for the increase of the vapour composition with the increasing of air temperature is due to the nonequilibrium driving force in microbubble distillation. The entropy of ethanol vapour is $282.7 \mathrm{~J} \cdot \mathrm{mol}^{-1} \cdot \mathrm{K}^{-1}$, and the entropy of the water vapour is $188.8 \mathrm{~J} \cdot \mathrm{mol}^{-1} \cdot \mathrm{K}^{-1}$ at $298.15 \mathrm{~K}$. Therefore, for the same quanta of enthalpy, the evaporation of one mole of ethanol achieves a higher increase in entropy than for the equivalent molar quantity of water. Maximum entropy is achieved by the selective evaporation of ethanol. Consequently, the vapour phase enrichment with ethanol in microbubble distillation was higher than the equilibrium proportion of the vapour composition. Similarly, increasing the air temperature yields preferential ethanol evaporation above the equilibrium proportion as the entropy increases with temperature.

This result clearly showed that microbubble distillation could achieve a higher separation efficiency of ethanol than with traditional distillation at certain liquid levels and

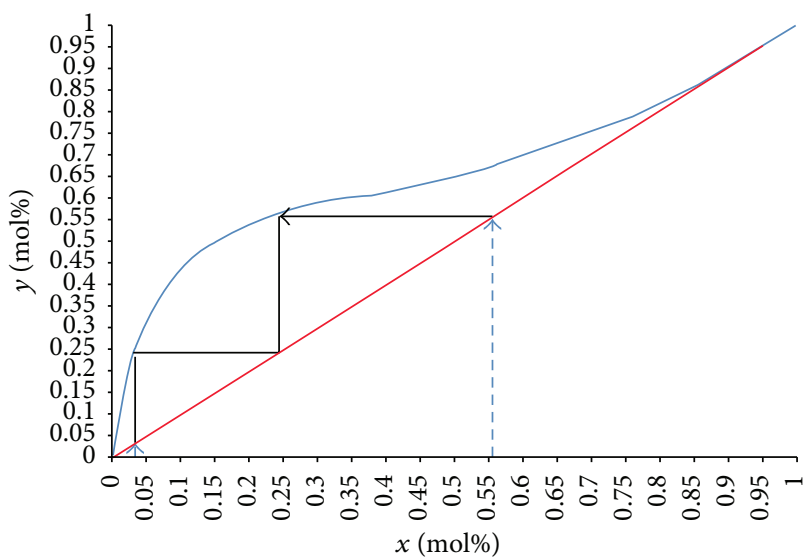

FIGURE 14: Number of ideal stages equivalent to separation efficiency of microbubble distillation batch system.

air temperatures. Also the separation efficiency could be increased by an increase of the air temperature at the same liquid concentration. Furthermore, the microbubble distillation system showed a vapour-liquid composition higher than the theoretical distillation column stage "ideal plates," while the single stage of commercial distillation column has an efficiency lower than that of the theoretical stage in which the vapour and liquid left the stage in thermodynamic equilibrium.

Microbubble distillation can mimic traditional distillation by assuming the distillation column works on a total reflux operation, and the overhead vapour concentration of the distillation column is the last fraction accumulated in the condenser and the residual liquid concentration is the final liquid concentration after the end of the experiment period. Consequently, the minimum number of theoretical stages can be estimated for a distillation column equivalent to that for the microbubble distillation unit.

Figure 14 shows the equivalent number of stages for microbubble distillation with a liquid concentration of $40 \%$ and an air temperature of $150^{\circ} \mathrm{C}$ at a liquid level of $3.5 \mathrm{~mm}$. The last fraction accumulated in the condenser after $80 \mathrm{~min}$ was $76.35 \%(55.8 \mathrm{~mol} \%)$ and the residual liquid concentration was $8.9 \%(0.03 \mathrm{~mol} \%)$. The distillation unit required a minimum of two stages to obtain the separation achieved by the microbubble distillation. It is worthwhile to mention that an actual distillation column requires a greater number of stages than the minimum number of the theoretical stages estimated by total reflux methods.

Although microbubble distillation shows the advantage of improving the separation efficiency over the traditional distillation, microbubble distillation is also more energy efficient in several respects when compared with traditional distillation. Microbubble distillation requires energy for heating the gas phase, while the liquid phase is heated in traditional distillation. The quanta of heat required for heating the gas phase are much lower than the quanta of heat required for raising the liquid temperature to the same level. The reason behind that is difference in the density and heat capacity of the air $(\rho c p)$ to that of the liquid (ethanol and water mixture 


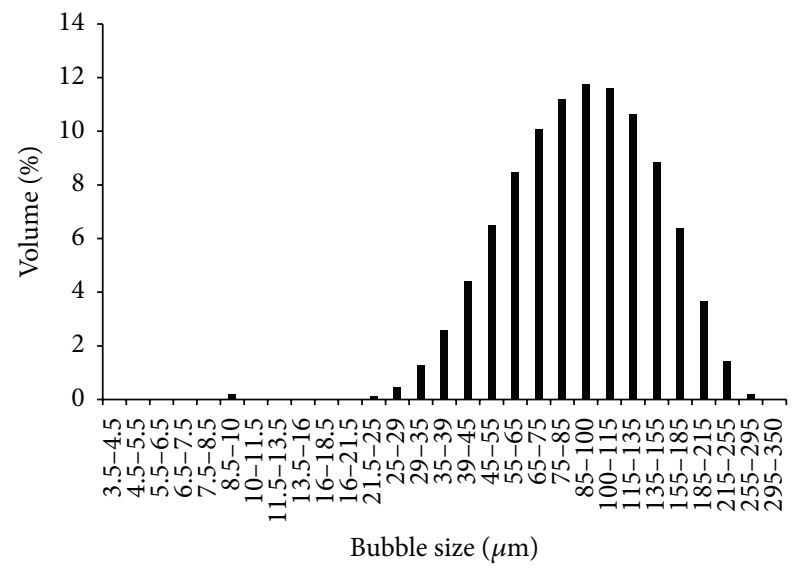

FIgURE 15: Bubble size distribution size under oscillatory flow at air flow rate of $1.5 \mathrm{~L} / \mathrm{min}$.

in current study). The quanta of energy consumed on heating the gas phase to a certain temperature will achieve higher separation if the same energy is used to heat the liquid phase. In addition, the mechanism of microbubble generation by an energy efficient fluidic oscillator reduced the energy required in the process. Reference [12] has reported that the fluidic oscillator has no moving parts and capable of producing a microbubble cloud without need of external energy. The generation of microbubbles by a fluidic oscillator only needs an air blower at an offset pressure that is slightly higher than the head of water [18]. By comparison, any other way of producing microbubbles leads to additional operational costs to the process.

3.2. Bubble Size Analysis. The bubble size distribution for microbubbles generated by the fluidic oscillator is shown in Figure 15. The bubble size measurement was conducted with flow rate of $1.5 \mathrm{~L} / \mathrm{min}$ and liquid mixture concentration of $40 \%$. The result shows a single peak bubble size distribution, indicating monodispersed and noncoalescent bubbles. It was shown that $50 \%$ of the bubbles that existed in the tested volume had a bubble size of $91 \mu \mathrm{m}$ and the Sauter mean bubble size was $78 \mu \mathrm{m}$ as listed in Table 1 .

The mechanism of generation microbubbles with using fluidic oscillator is based on releasing the bubble during the early step of growing. Also, the presence of ethanol in the liquid mixture reduced the surface tension of the liquid which enhanced the reduction of bubble size formed $[19,20]$.

3.3. Comparison with Pervaporation. The results of the microbubble distillation achieved a high separation efficiency with a minimum increase of liquid temperature. This feature of the microbubble distillation technology could meet the pertinacious limitations in the separation of thermally sensitive mixtures. Microbubble distillation of ethanol-water mixtures could be applied for the recovery/production of bioethanol from fermentation broths. Bioethanol is widely used in the production of beverages and as an important source of renewable fuels.
TABLE 1: Bubble size analysis.

\begin{tabular}{llcc}
\hline$D[3,2]$ & $D v(90)$ & $D v(50)$ & $D v(10)$ \\
\hline $78 \mu \mathrm{m}$ & $164 \mu \mathrm{m}$ & $91 \mu \mathrm{m}$ & $47 \mu \mathrm{m}$ \\
\hline
\end{tabular}

Several techniques have been performed to recover ethanol from the fermentation broths, and these methods take the thermal sensitivity of the fermentation broths into consideration [21]. Gas stripping is an established technique for continuous ethanol removal during fermentation processes. Different gases such as nitrogen and $\mathrm{CO}_{2}$ have been widely used in a wide variety of processes as they do not adversely affect culture media $[5,22]$.

A number of studies were carried out in order to test the extent to which pervaporation could serve as a viable method of recovering ethanol from the fermentation medium [2325]. The concept of the pervaporation is selective separation of volatile products from the liquid feed mixture by utilizing membranes. The liquid feed mixture is heated to a certain temperature to bring the components into a vapour phase at sufficient vapour pressure. The vapour comes into contact with the membrane, which allows selective separation of the components. A pressure differential made across the feed side and permeate side results in a flux of vapour containing a higher concentration of the desired component passing through to the condenser.

Selectivity is a measure of the ability of the membrane to allow the permeation of a specific component. A dimensionless quantity $(\beta)$ known as the separation factor represents the membrane selectivity which is dependent on the concentration of the desired component in feed and permeate:

$$
\beta=\left(\frac{x_{i p}}{1-x_{i p}}\right)\left(\frac{1-x_{i f}}{x_{i f}}\right),
$$

where $x_{i p}$ and $x_{i f}$ are the fractions of selective component in the feed and permeate, respectively.

In order to compare between the separation of the ethanol and water mixture by microbubble distillation and the separation by pervaporation, the dimensionless separation factor is reformatted to fit the microbubble distillation outcomes in a way that maintains the concept and the function of the factor which indicates the efficiency of the separation:

$$
\beta_{m}=\left(\frac{x_{i c}}{1-x_{i c}}\right)\left(\frac{1-x_{i f}}{x_{i f}}\right)
$$

where $\beta_{m}$ is the separation factor of the microbubble distillation and $x_{i c}$ and $x_{i f}$ are the fractions of the ethanol in vapour phase and in initial concentration of the solution.

Figure 16 shows the separation factor for microbubble distillation as a function of the feed concentration. The separation factor for microbubble distillation unit was 12.3 at a liquid concentration of $10 \%$ and decreased by increasing the ethanol concentration to reach 6.69 at a liquid concentration of $40 \%$.

The type of the membrane used in the pervaporation played an important role on the separation efficiency and 


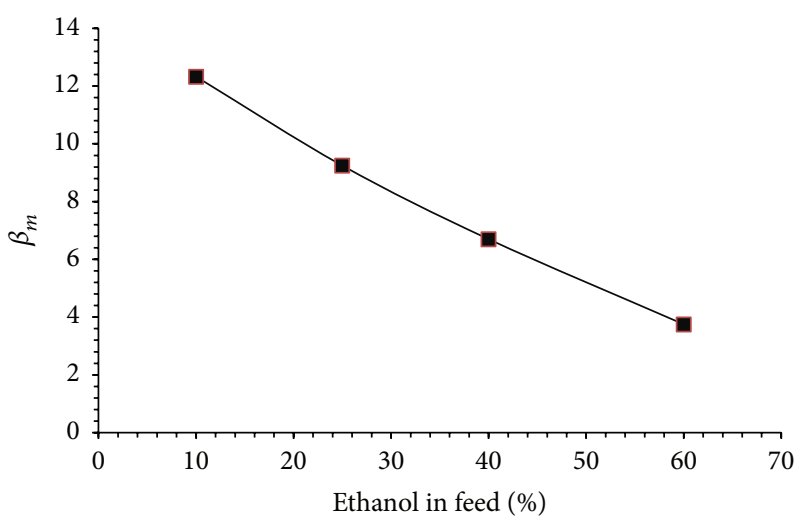

FIGURE 16: Separation factor for microbubble distillation at air temperature of $150^{\circ} \mathrm{C}$.

the separation factor. The separation factor was around 11 for a feed concentration of $10 \%$, and the separation factor decreased by increasing the concentration when different cellulose acetate membranes are used in the pervaporation [6]. A similar result was shown with silicone rubber membranes; the separation factor was around 8.5 for a feed concentration of $10 \%$ for a PPMS membrane, where the separation factor decreased by increasing the concentration [26]. However, the separation factor increased to around 60 with an ethanol concentration of $10 \%$ by using a silicate membrane at a $30^{\circ} \mathrm{C}$ feed temperature [24].

One of the general drawbacks of the pervaporation process is the low permeation rate, which is increased by maximizing the feed concentration and temperature [27]. However, fermentation broths are thermally sensitive and the concentration of the ethanol is relatively low. Another disadvantage of the membrane process is the membranes' thermal and chemical stability [28]. This factor limits the lifetime of the membrane in long term. Although the energy consumption of pervaporation process is low compared to that of distillation processing, the energy required to create the vacuum used in the latter stages of the process may add a significant energy load.

The recovery of ethanol from the broth by distillation is a complex process and consumed more than half of the total energy required to produce the bioethanol by fermentation [4]. Overall, microbubble distillation was shown to be a promising technology to recovery of bioethanol from fermentation broths. Microbubble distillation showed a high energy and separation efficiency over traditional distillation. The liquid level and the air temperature could be optimized to find the best conditions to achieve a higher separation and prevent overheating of the medium.

\section{Conclusion}

In the current study, microbubble distillation for ethanol and water was investigated. The comparison between the microbubble distillation and traditional distillation shows that the microbubble distillation can be controlled to achieve higher separation efficiency. The vapour-liquid composition results from the microbubble distillation at air temperature of $150^{\circ} \mathrm{C}$ were higher than that of equilibrium vapourliquid composition. In addition, effect of air temperature was investigated with liquid concentration of $25 \%$ and $40 \%$ and the results showed that the efficiency of separation can be increased by an increase in the air temperature. Although the liquid temperature increased with the increase of the air temperature, it was significantly less than the boiling point of the mixture. Furthermore, traditional distillation required more than two ideal stages to equal the separation efficiency of a batch microbubble distillation unit. The enhancement of the separation efficiency in microbubble distillation is accompanied by improvement in energy consumption achieved by the method of generating the microbubble and the concept of heating the air stream in microbubble distillation. Microbubble distillation can be applied to recovery of bioethanol and achieve a separation factor of 12.3 at a liquid concentration of $10 \%$. The pertinent demand for enhancing the energy and separation efficiency has been achieved with microbubble distillation. Finally, microbubble distillation is a new technology that shows a great deal of potential use within bioethanol recovery from fermentation media and separation of thermally sensitive mixture.

\section{Competing Interests}

The authors declare that they have no competing interests.

\section{Acknowledgments}

William B. Zimmerman thanks Innovate UK and EPSRC for a grant under the IB Catalyst industrial research scheme, EP/N011511/1. Atheer Al-yaqoobi thanks the Iraqi Ministry of Education for a doctoral scholarship.

\section{References}

[1] J. F. Richardson, J. H. Harker, and J. R. Backhurst, Coulson and Richardson's Chemical Engineering, vol. 2, ButterworthHeinemann, Oxford, UK, 2002.

[2] U. M. Diwekar, Batch Distillation: Simulation, Optimal Design, and Control, CRC Press, New York, NY, USA, 2011.

[3] W. L. McCabe, J. Smith, and P. Harriott, Unit Operations of Chemical Engineering, McGraw-Hill Chemical Engineering, McGraw-Hill Education, 2005.

[4] S.-I. Nakao, F. Saitoh, T. Asakura, K. Toda, and S. Kimura, "Continuous ethanol extraction by pervaporation from a membrane bioreactor," Journal of Membrane Science, vol. 30, no. 3, pp. 273287, 1987.

[5] J. L. S. Sonego, D. A. Lemos, G. Y. Rodriguez, A. J. G. Cruz, and A. C. Badino, "Extractive batch fermentation with $\mathrm{CO}_{2}$ stripping for ethanol production in a bubble column bioreactor: experimental and modeling," Energy \& Fuels, vol. 28, no. 12, pp. 7552-7559, 2014.

[6] P. Kaewkannetra, N. Chutinate, S. Moonamart, T. Kamsan, and T. Y. Chiu, "Separation of ethanol from ethanol-water mixture and fermented sweet sorghum juice using pervaporation membrane reactor," Desalination, vol. 271, no. 1-3, pp. 88-91, 2011. 
[7] L. M. Vane, "A review of pervaporation for product recovery from biomass fermentation processes," Journal of Chemical Technology and Biotechnology, vol. 80, no. 6, pp. 603-629, 2005.

[8] W. B. Zimmerman, M. K. H. Al-Mashhadani, and H. C. H. Bandulasena, "Evaporation dynamics of microbubbles," Chemical Engineering Science, vol. 101, pp. 865-877, 2013.

[9] R. C. Pemberton and C. J. Mash, “Thermodynamic properties of aqueous non-electrolyte mixtures II. Vapour pressures and excess Gibbs energies for water + ethanol at 303.15 to $363.15 \mathrm{~K}$ determined by an accurate static method," The Journal of Chemical Thermodynamics, vol. 10, no. 9, pp. 867-888, 1978.

[10] A. Al-Yaqoobi and W. B. Zimmerman, "Microbubble distillation studies of a binary mixture," in Proceedings of the University of Sheffield Engineering Symposium Conference (USES '14), June 2014.

[11] W. B. Zimmerman, V. Tesař, and H. C. H. Bandulasena, "Towards energy efficient nanobubble generation with fluidic oscillation," Current Opinion in Colloid and Interface Science, vol. 16, no. 4, pp. 350-356, 2011.

[12] W. B. Zimmerman, V. Tesař, S. Butler, and H. C. H. Bandulasena, "Microbubble generation," Recent Patents on Engineering, vol. 2, no. 1, pp. 1-8, 2008.

[13] W. B. Zimmerman, M. Zandi, H. C. Hemaka Bandulasena, V. Tesař, D. James Gilmour, and K. Ying, "Design of an airlift loop bioreactor and pilot scales studies with fluidic oscillator induced microbubbles for growth of a microalgae Dunaliella salina," Applied Energy, vol. 88, no. 10, pp. 3357-3369, 2011.

[14] B. Hadrich and N. Kechaou, "Identification of best model for equilibrium data of ethanol-water mixture," Journal of Chemistry and Chemical Engineering, vol. 4, pp. 1934-7375, 2010.

[15] I. C. Arango and A. L. Villa, "Isothermal vapor-liquid and vapor-liquid-liquid equilibrium for the ternary system ethanol + water + diethyl carbonate and constituent binary systems at different temperatures," Fluid Phase Equilibria, vol. 339, pp. 3139, 2013.

[16] V. Niesen, A. Palavra, A. J. Kidnay, and V. F. Yesavage, "An apparatus for vapor-liquid equilibrium at elevated temperatures and pressures and selected results for the water-ethanol and methanol-ethanol systems," Fluid Phase Equilibria, vol. 31, no. 3, pp. 283-298, 1986.

[17] E. M. Queiroz, Transferência Simultânea de Calor e Massa em Processos de Borbulhamento, COPPE/UFRJ, Rio de Janeiro, Brazil, 1990.

[18] J. Hanotu, H. C. H. Bandulasena, T. Y. Chiu, and W. B. Zimmerman, "Oil emulsion separation with fluidic oscillator generated microbubbles," International Journal of Multiphase Flow, vol. 56, pp. 119-125, 2013.

[19] H. Chaumat, A. M. Billet, and H. Delmas, "Hydrodynamics and mass transfer in bubble column: influence of liquid phase surface tension," Chemical Engineering Science, vol. 62, no. 24, pp. 7378-7390, 2007.

[20] A. A. Mouza, G. K. Dalakoglou, and S. V. Paras, "Effect of liquid properties on the performance of bubble column reactors with fine pore spargers," Chemical Engineering Science, vol. 60, no. 5, pp. 1465-1475, 2005.

[21] L. M. Vane, "Separation technologies for the recovery and dehydration of alcohols from fermentation broths," Biofuels, Bioproducts and Biorefining, vol. 2, no. 6, pp. 553-588, 2008.

[22] T. de Vrije, M. Budde, H. van der Wal, P. A. M. Claassen, and A. M. López-Contreras, “'In situ' removal of isopropanol, butanol and ethanol from fermentation broth by gas stripping," Bioresource Technology, vol. 137, pp. 153-159, 2013.

[23] J. H. B. Jaimes, M. E. T. Alvarez, J. V. Rojas, and R. M. Filho, "Pervaporation: promissory method for the bioethanol separation of fermentation," Chemical Engineering Transactions, vol. 38, pp. 139-144, 2014.

[24] T. Sano, H. Yanagishita, Y. Kiyozumi, F. Mizukami, and K. Haraya, "Separation of ethanol/water mixture by silicalite membrane on pervaporation," Journal of Membrane Science, vol. 95, no. 3, pp. 221-228, 1994.

[25] S. Sharma and G. P. Rangaiah, "Modeling and optimization of a fermentation process integrated with cell recycling and pervaporation for multiple objectives," Industrial and Engineering Chemistry Research, vol. 51, no. 15, pp. 5542-5551, 2012.

[26] X. Han, L. Wang, J. Li, X. Zhan, J. Chen, and J. Yang, "Separation of ethanol from ethanol/water mixtures by pervaporation with silicone rubber membranes: effect of silicone rubbers," Journal of Applied Polymer Science, vol. 119, no. 6, pp. 3413-3421, 2011.

[27] M. H. V. Mulder, J. O. Hendrickman, H. Hegeman, and C. A. Smolders, "Ethanol-water separation by pervaporation," Journal of Membrane Science, vol. 16, pp. 269-284, 1983.

[28] H. M. Van Veen, Y. C. Van Delft, C. W. R. Engelen, and P. P. A. C. Pex, "Dewatering of organics by pervaporation with silica membranes," Separation and Purification Technology, vol. 22-23, pp. 361-366, 2001. 


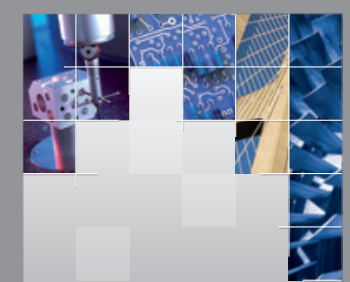

\section{Enfincering}
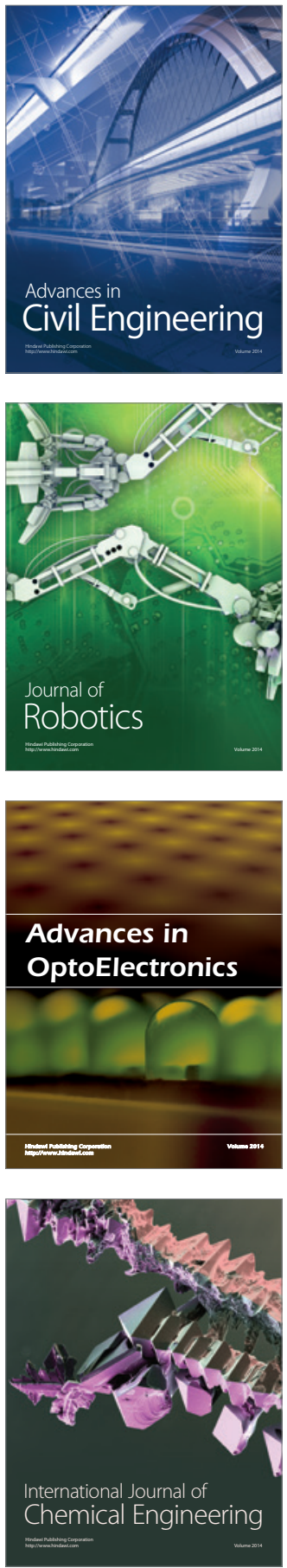

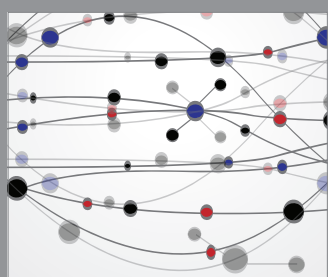

The Scientific World Journal

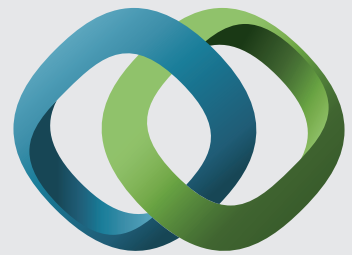

\section{Hindawi}

Submit your manuscripts at

http://www.hindawi.com
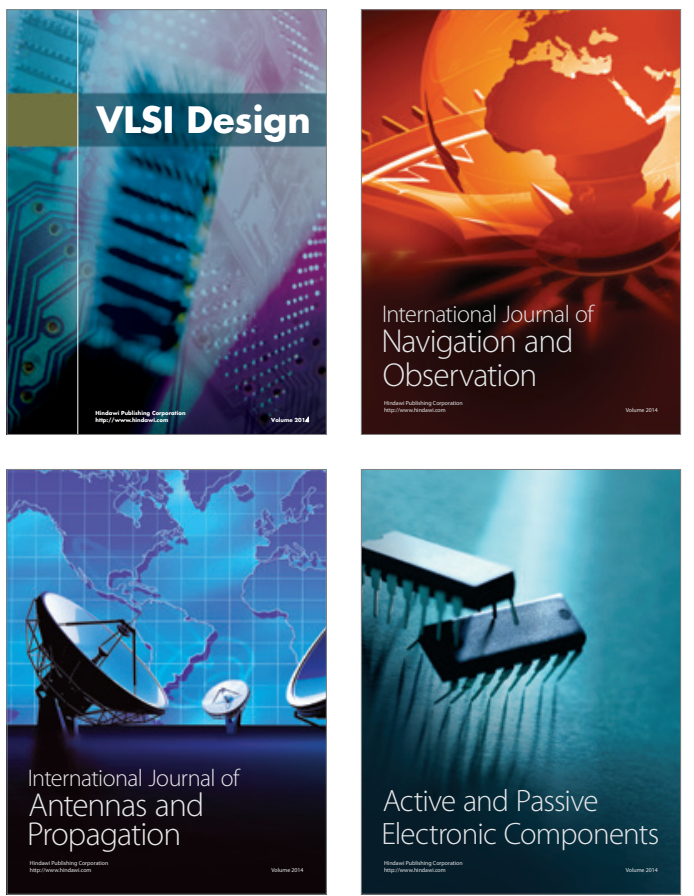
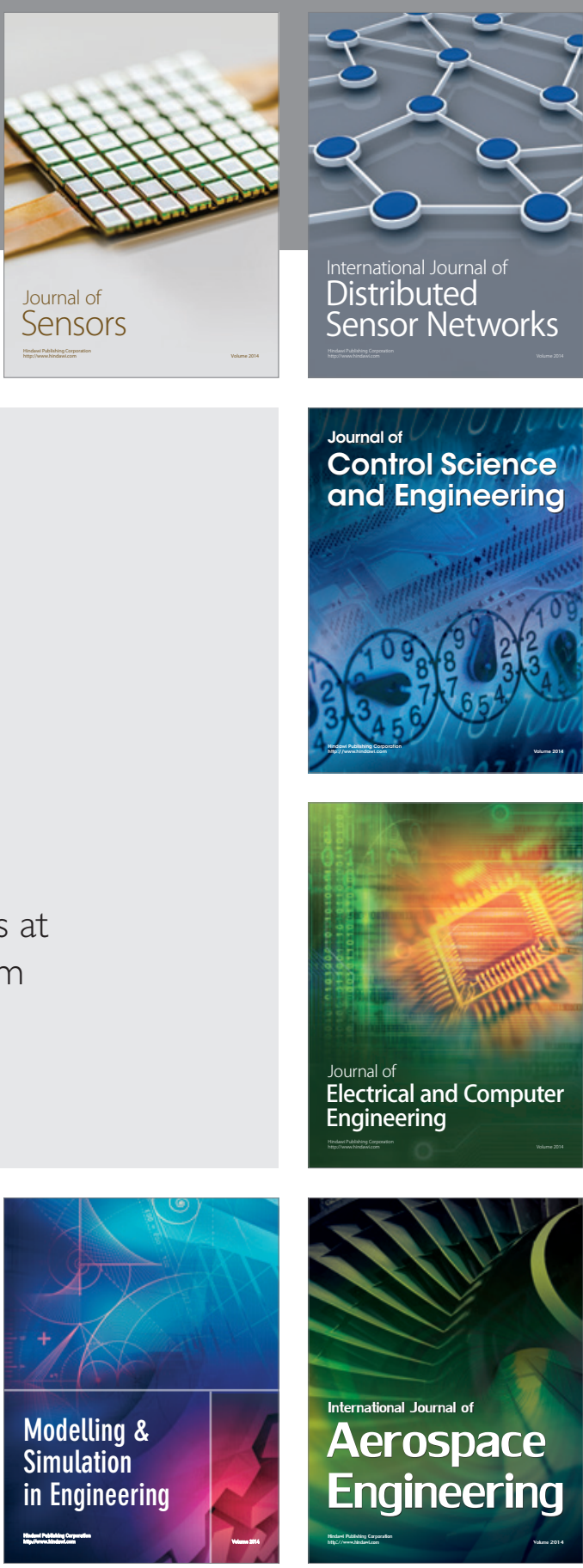

International Journal of

Distributed

Sensor Networks

Journal of

Control Science

and Engineering
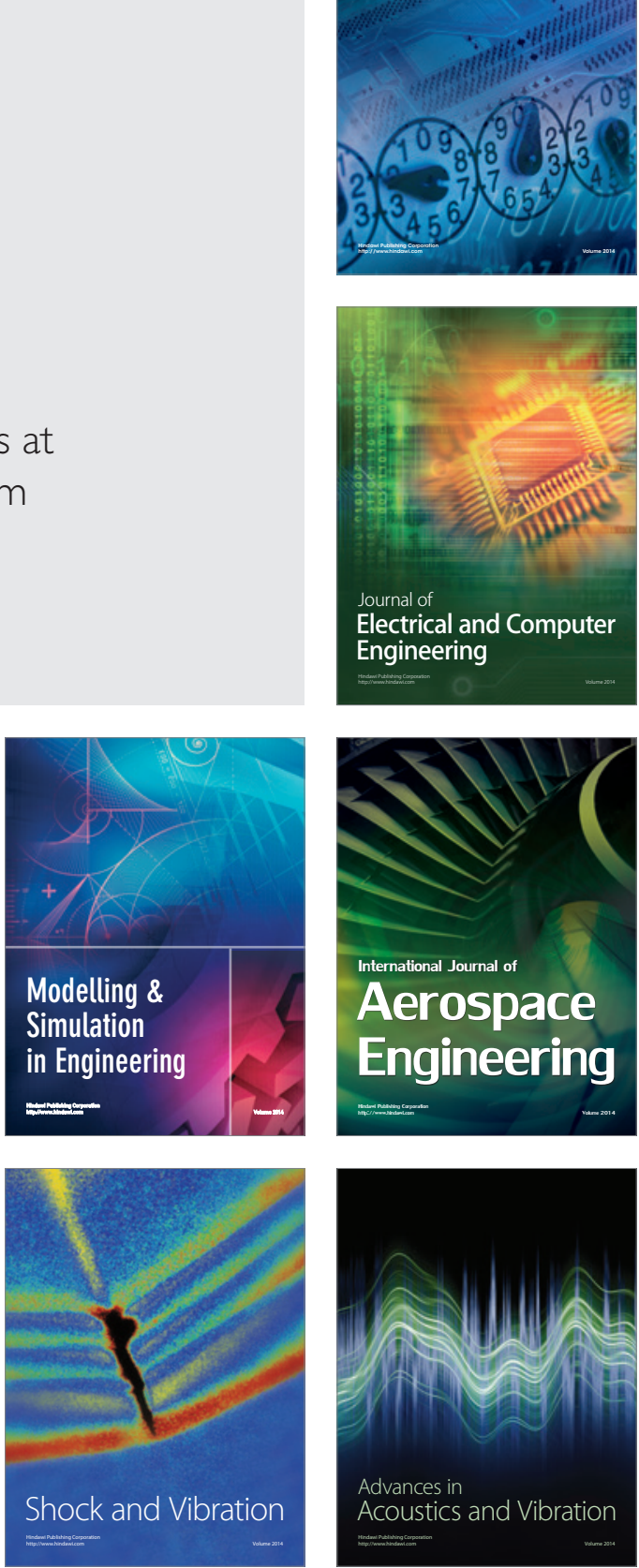